\title{
The European Supervisory Authorities: role-models or in need of re-modelling?
}

\author{
Kostas Botopoulos 1
}

Published online: 26 May 2020

(C) The Author(s) 2020

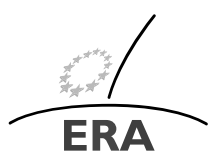

EUROPÄISCHE RECHTSAKADEMIE ACADEMY OF EUROPEAN LAW ACADEMIE DE DROIT EUROPEEN ACCADEMIA DI DIRITTO EUROPEO
TRIER - TREYES - TREVIRI

\begin{abstract}
The three European Supervisory Authorities (ESAs) are, for almost a decade now, part of the financial landscape, arbiters as well as players in what has turned out to be a complex and frail system. They have served well, but should they remain unchanged? The present article analyses the way they were conceived and set up, their architecture, their legal and substantive characteristics and deals with the question of their reform.
\end{abstract}

Keywords European Supervisory Authorities (ESAs) - Agencies plus · Review vs reform · Capital Markets Union

\section{Crisis, what crisis?}

\subsection{Raison-d-etre}

Global crises beget international institutions: it has been true with two out the three major financial crises of the 20th and 21st century. Only the 1929 crash, mainly impacting the USA in what was then an un-globalised era, was dealt with mostly internally, by means of the New Deal policy mix; the end of the two world wars and the financial disruption it created gave birth (1944) to the Bretton Woods institutions: the International Monetary Fund, the World Bank and, at a deeper level, the so-called "Washington consensus" whose laissez-faire spirit permeated financial activities and financial supervision for decades; whereas the crisis of 2009, in a wholly globalised

Doctor of Constitutional Law, ex Chair of the Hellenic Capital Markets Commission, member of the ESMA Board of Supervisors and Management Board, and today representative of the Bank of Greece at the EBA

K. Botopoulos

1 Bank of Greece, 21 E. Venizelos Ave, 10250 Athens, Greece 
environment, was at the epicentre of the G-20 Summit in Pittsburgh, which confirmed the urgency of more regulation as well as supra-national supervision of financial activities and produced, at European Union level, the three ESAs.

Although the premises were there for everyone, and mainly the already existing specialised bodies, to see, the crisis acted as a catalyst by presenting the world, and primarily its political leaders, with an amplifying mirror in which the main flaws of the financial system were reflected: risk, often excessive risk, and surely cross-border risk, went undetected; supervision was uncoordinated and ineffective; systemic issues were ignored; decision-making was slow and topical; not only was there not any confidence in the system but the system entirely lacked confidence-building mechanisms.

The "de Larosière Report"1 phrased it succinctly: the then existing EU arrangements placed "too much emphasis on the supervision of the financial firms and too little on the macro-prudential side"; "there was no mechanism to ensure that the assessment of risk was translated into action"; "the processes and practices for challenging the decisions of a national supervisor have proven to be inadequate"; "information flow among supervisors was far from optimal". All in all, it was stated without ambiguity that "the crisis-prevention function of supervisors in the EU has not performed well and is not fit for purpose". The remedy was also unambiguous: the creation of a European system of supervision and crisis management, in place of the uncoordinated system of quasi-supervision fit only for "normal" times. ${ }^{2}$ It is certainly not by accident that in the founding texts of the three ESAs ${ }^{3}$ the first Recitals of the Preamble formally states that "The financial crisis of 2017 and 2018 exposed important shortcomings in financial supervision ... in the areas of cooperation, coordination, consistent application of Union law and trust between national supervisors". The link between the ESAs and the crisis could not be more direct.

\subsection{A network}

Though deeds are more important than words, words do matter. For the issue at hand, three plus one words: "system", i.e. a complete and, as much as possible, integrated mechanism instead of disparate entities and actions; "European", meaning supervision at supra-national level and in the name of a supra-national/pan-European interest; and "management", i.e. actions attuned to systemic risks and factors constituting a threat to the stability of the whole financial system and with the potential of disrupting the real economy. ${ }^{4}$ Thus, were the main supervisory flawsneglect of the global/systemic factors, national priorities/focus, uncertainty about processes/actions - to be tackled. The logical implications, spelled out in the de

\footnotetext{
${ }^{1}$ In November 2008, the European Commission mandated a High-Level Group on financial supervision presided by, and named after, the former President of the FMI and prominent macro-economist Jacques de Larosière. The Group rendered a 2009 report, in which it analysed the effects of the crisis and proposed the creation of the three ESAs.

${ }^{2}$ Recital 8 of the founding Regulations: "The Union has reached the limits of what can be done with the present status".

${ }^{3}$ Regulations 1093/2010 for EBA, 1094/2010 for EIOPA and 1095 for ESMA.

${ }^{4}$ Anderson [1].
} 
Larosière Report, were the creation of a macro-prudential oversight mechanism, called the "European Systemic Risk Council" in the Report and subsequently established as the European Systemic Risk Board (ESRB), and of a European supervisory network, the European System of Financial Supervisors (EFSF), comprising the ESRB, the three newly created European Supervisory Authorities (the ESAs) and the competent national authorities. "Network" is the fourth important-potentially even the most important—word, by its implications of a 'well-oiled' macro and micro, national and supranational, regulatory and supervisory mechanism. 'Well-oiled' ... well, in theory ... complexity being, from the very outset, the name of the game.

The main elements of the proposal found their way in legal texts and became reality: a not legally binding macro-prudential function, the ESRB emitting recommendations, not decisions, and "imposing" them by a "comply or explain" mechanism; three sectoral European supervisory "authorities" (we will be coming to the nomenclature issue in due time), one for the banking sector (European Banking Authority-EBA, based, at least initially, near the City of London), one for the financial markets (European Securities and Markets Authority-ESMA, based in not-only-cultural Paris) and one for the insurance sector (European Insurance and Pensions Authority-EIOPA, based near the ECB in Frankfurt): all institutions were created not from scratch but by an upgrading of the existing advisory committees ${ }^{5}$ (CEBS, CESR and CEIOPS, respectively), each acting independently (we shall also revisit the independence issue) but in close collaboration; ${ }^{6}$ and a mixed organisational model, combining supranational elements such as the Chairs and personnel of the three ESAs, action in the name of the European interest, qualified majority voting in restricted cases, with a strong national representation. For example the composition of the Boards of Supervisors, both at ESAs and ESRB level, the rule of "one man-one vote" for the normal voting procedure, the importance of the national supervisors.

Some inherent flaws were also present from the very inception: the ESRB was too "banco-centric", not only hosted by the ECB, but composed mainly by banking supervisors: the President and Vice-President of the ECB, the 27 Governors of the European Central Banks and only the three Chairpersons of the ESAs and one representative of the European Commission; the network was, by default, too loose; and, most importantly, and partly in contradiction with the de Larosière report, which had pleaded for providing the ESAs with some measure of proper decision-making, in particular by adopting binding technical standards, ${ }^{7}$ the prevalence of the idea that decision-making would remain mainly in the hands of national supervisors, thus permeating the system which had engendered the crisis.

Despite the relative lack of ambition, the quantitative leap is evident: reacting to the crisis and acting swiftly-the new mechanism would be in place within 20 months, at the beginning of 2011-, the European decision-makers passed from the

\footnotetext{
${ }^{5}$ Thus the introduction of the ESAs was "incremental" from the very beginning. See Moschella/Tsingou (eds.) [12]. The notion of "incrementalism" regarding the ESAs appears also in the work of Aneta Spendzharova on financial reform.

${ }^{6}$ In Recital 8 of the founding Regulations the expression "strong Union network" are used; in Recital 9, "an integrated network". The 2009 Communication of the Commission refers to an "operational European network with shared and mutually reinforcing responsibilities".
}

${ }^{7}$ Scholten/Ottow [13]. 
mostly procedural "Lamfalussy approach", vis-a-vis financial regulation ${ }^{8}$ to a fullyfledged crisis-management approach by creating and empowering new institutions, promoting the idea of international and supranational cooperation and pressuring for maximum harmonisation. One may seriously argue that the crisis was not lost on the EU in this instance; but this should not be construed as meaning that crises will be averted henceforth or that the system is perfect.

\section{Triplets, torn apart}

\subsection{A common framework}

The three ESAs have not only been created together, they have been conceived together and meant to work together. Their most obvious common point is their legal framework: the three founding Regulations are almost identical in everything, including the respective competences. Was this a deliberate choice or just laziness on the part of the Commission and the co-legislators? On the one hand, it could be perceived as the easy way to upgrade the existing advisory Committees, which did not benefit from such legal texts, and to create the impression of a ready-to-use network. On the other, it could be argued that the needs of the banking, capital markets and insurance sectors were interconnected but different, thus warranting at least some special arrangements: the priority of tasks and the tools of supervision are obvious examples. It is worth noting that the European Parliament used the EBA Regulation as a template, "that text being considered applicable nec varietur to the two other authorities", 9 and thus debated as if the financial sector consisted only, or mainly, of banks, ignoring, inter alia, that a) banks were not the primary cause of the crisis, b) there existed already another supervisor for the banks in the European Union, having, moreover, the rank of "institution". Reality of both the markets and the ESAs' operation would take on the task of making the divergences apparent.

All three founding regulations are divided into seven chapters. The first deals with the "Establishment and legal status" of each ESA covering also the "general objectives" and the ESAs' position within the EFSF. The second, most important and extensive chapter, defines the "tasks and powers". "Tasks" defined by art. 8.1 of the founding Regulations are everything they do or supposed to be doing: impose high-quality common regulatory and supervisory practices, consistent application of Union acts, delegate responsibilities with and among national competent authorities (NCAs), cooperate with the ESRB, conduct peer reviews, follow market developments, do market analyses in the respective fields, protect investors, participate in colleges of supervisors, publish and update information; whereas "powers" aremostly-the means by which they perform their duties: emitting draft regulatory

\footnotetext{
${ }^{8}$ Named after its inspirer and adopted by the EU in 2001, it consisted of organising financial legislation and supervision according to a hierarchy of norms, "Level I" measures meaning EU legislation, "Level II" technical measures adopted by the Commission, "Level III" guidance by the then existing financial Committees. The system has survived the creation of the ESAs, but the ESAs have ascended to "Level 2,5 " status by implementing technical standards to be adopted by the Commission.

${ }^{9}$ Wymeersch [20].
} 
technical standards and implementing regulatory standards, issuing guidelines and recommendations, taking individual decisions, giving opinions, gathering and providing information, creating common methodologies, developing databases. Chapter two also deals with other tasks or "powers" outside the main catalogue but equally, if not more, important: breach of union law known as BUL, emergency situations, settlement of disagreements, colleges, systemic risk, common supervisory culture, coordination, international relations; it also puts in place some specific common arrangements: the setting up of Stakeholders Groups, the so-called "safeguards", i.e. a general exception on behalf of member-states (see third section), and decisionmaking procedures. Chapter three is entitled "Organisation" and refers to the Board of Supervisors and decision-making therefrom, the Management Board, the Chairperson and the Executive Director. Chapter four entitled "Joint bodies" sets up a "Joint Committee" which is only one organ but thrice replicated and the respective Boards of Appeals. Chapter five "Remedies" deals with appeals and actions before the European Court of Justice and chapter six "Financial Provisions" with the budget, both as a means and a mechanism, as well as with anti-fraud theoretical protection. Chapter seven is, by definition, pot-pourri titled "General" it deals with privileges and immunities, staff matters, liabilities, personal secrecy, data protection and access to documents, language, headquarter arrangements, third-country regimes, while the last chapter encompasses transitional provisions facilitating the passage from "advisory Committees" to "Authorities"; it also sets an important review clause: the functioning of the ESAs was to be reviewed by January 2024 and every three years thereafter.

This common legal background provided identity - in both senses of the term: it created legal persons and made them equal-but by no means certainty and clarity.

\subsection{Regulators, supervisors, mediators}

From above exhaustive reference to the ESAs legal framework it should have become apparent that a cumulative approach was chosen by the legislators: we have lists of what the ESAs do or are supposed to be doing but not clear delineations of what their competences and attributions are. Instead, duplications and misconceptions abound, the distinction between "objectives", "powers", and "tasks" is unhelpful and sometimes misleading. ${ }^{10}$ To shed some light, we must revert to synthesis.

I would say that each ESA is a three-headed beast: a regulator, a supervisor, a mediator-in that order. Regulation, i.e. rule-making power, was not meant to be the primary focus - after all the three authorities were supposed to be "supervisory" by their very name. Institutional design, however, assisted by the "shopping-list" method of setting out competences, as well as the needs of the moment, upgraded the regulatory role.

Even if in theory subject to the Commission's approval-the final founding texts referred not to "binding technical standards" but to "draft" technical standards- the

\footnotetext{
${ }^{10}$ Some examples: "consumer protection" is an "objective", while "investor protection" a "task"; peer reviews and "market developments" are both under "tasks"; the need to refer to "any other task" was felt to be necessary in all three founding Regulations; use of information by the ESAs was listed both under the tasks and the powers; economic analyses are a task, whereas common economic methodologies a power.
} 
rule-making responsibilities of the ESAs, namely their obligations to set up and propose to the Commission Regulatory Technical Standards (RTSs) and Implementing Technical Standards (ITSs), have become, by far, their main task, taking up the bulk of their resources and energy. The fact the ESAs were, by their very inception, considered to possess the necessary expertise (an important notion which we shall revisit in the next two sections), without which the legislative rules in the financial sector would remain an empty shell, coupled with the reality that the RTSs and ITSs have very seldom been rejected by the Commission and have most of the time been prepared in close collaboration between the competent authority and the relevant Commission services, ${ }^{11}$ has made the technical measures not only binding as soon as adopted, but also quasi-obligatory for the Commission upon "proposal" which was, in fact, submission.

Moreover, the very Regulations shifted the balance of power on behalf of the ESAs by providing that the Commission could amend or reject the draft standards "only in very restricted and extraordinary circumstances", those being defined as incompatibility with Union law, no respect of the principle of proportionality and breach of fundamental principles of the internal markets". ${ }^{12}$ With such a caveat, and on the basis of the also legally enshrined expertise of the ESAs, the rule that the draft standards should limit themselves to technicalities and not impinge on strategic decisions or policy choices became almost purely theoretical: there can be no other strategist than the expert, especially when the supposed main strategist, the Commission, has very few possibilities for objection and, moreover, the dividing line between "purely technical" and "somewhat political" standards is very hard to draw. ${ }^{13}$

All in all, this is "quasi-rulemaking" bordering on plain rulemaking. ${ }^{14}$ The fact that, especially in the first cycle of the ESAs' existence, regulation was so intensethe financial industry, not always in good faith but not off the mark either, coined the term "regulatory tsunami" - contributed in making regulatory work what the ESAs, and especially ESMA, were mostly occupied with. The creation and constant enrichment of a "Single-Rule Book", a set of harmonised prudential rules, became, both by design and necessity, a primary objective, in line with the crisis-driven requirements of more regulation, maximum harmonisation, very detailed standards and the famous - albeit often vacuous - need to ensure a "level playing field".

Furthermore, again because the ESAs were children of the crisis, a large spectrum of emergency powers, which one could qualify as "decision-making in urgency", were attributed to them: remedial actions (binding decision taken by the ESAs in emergency situations declared by the Council), temporary restrictions of products or activities threatening the orderly functioning and integrity of the financial markets (emergency here being judged by the ESAs themselves), as well as the supposedly important but in fact very ambiguous "breach of (EU) law" procedure, whereby the

${ }^{11}$ This gave rise to a formal arrangement in "navette" form — texts would need to go and forth between the ESA preparatory groups and Commission services-in 2014.

${ }^{12}$ Recital 23 of Regulations 1093 and 1095/2010, and 22 of Regulation 1094/2010. See in detail, De Bellis [6].

${ }^{13}$ Kost de Sevres/Sasso [8].

${ }^{14}$ On the advanced rule-making powers that the ESAs have been provided with compared to their predecessors and other EU agencies, see Tsangas [16]. 
ESAs have a role of verifying and, in case of breach, taking binding remedial measures towards establishing the correct implementation of EU financial legislation. That the emergency powers have very rarely been used since the ESAs started functioning and that the few cases of BUL examined have led, as I have had the opportunity to experience first-hand both at ESMA and EBA, to inconclusive results, should not deter from the fact that such binding regulatory powers are there for the ESAs to use and potentially come to terms with.

Parts of the "analysis" provided by the ESAs in the form of information or interpretation, as well as further authoritative assistance provided through guidelines and instructions, required by sectoral legislation or drafted by own initiative, theoretically advisory but in practice binding work by the ESAs, completes the regulatory competences and enhances their status. The "supervisory" authorities have proven to be, at least during the initial period, mostly regulatory authorities - and this apparent disharmony explains why, beginning from the first ESAs review in 2014, and gathering momentum since, there has been a clear a shift towards focusing more on supervisory convergence.

Supervision is what the ESAs were mostly meant to be doing, but it has been hampered by a series of factors.

Firstly, and most importantly, by the political decision that supervision should remain largely decentralised, exercised at member-state level by the respective national competent authorities. Thus, direct supervisory powers attributed to the ESAs are very scarce: supervision of Credit Rating Agencies (CRAs) and Trade Repositories (TRs) for ESMA ${ }^{15}$ - more were to come with the 2019 revision, as will see at the last section-and, indirectly, stress-testing of banks by EBA. ${ }^{16}$ "Centralisation" of data has also progressively become a feature, with ESMA leading the way by a BoS decision on the eve of the entry into force of MIFID2/MIFIR, and EBA following for the gathering of banking data.

Secondly, because the very notion of "supervisory convergence" in a constellation of 28 member-states - soon to become 27, but, in the financial sector, we will be losing a real driving force-, and with the supra-national decision-making bodies composed by national representatives, is an elusive, if not allusive, notion. Convergence is less a supervisory task than a cultural enterprise, and thus the transition from quasi-rulemaking to convergence will take time and depends more on broader political evolutions than on ESA initiatives.

And thirdly, because the tools provided to the ESAs for their supervisory taskson-site inspections, peer reviews, Q \& As, risk-assessments on a higher level ${ }^{17}$ —, although rather comprehensive on paper, lack imagination and have proven to be more

\footnotetext{
${ }^{15}$ The case for more direct supervisory powers for the ESAs and especially ESMA is strongly made by Busch [2].

${ }^{16}$ Controversy has at the beginning surrounded the acquittal of this task by EBA. The European Court of Auditors published on the 2nd of July 2014 found, regarding the 2011 tests, that "EBA had neither the staff nor the necessary mandate to ensure the reliability of the stress test exercise".

${ }^{17}$ The adventure of a joint draft technical standard (November 2015) by the three ESAs on how to assess methodologies by the credit rating agencies measuring credit risk, which was not accepted by the Commission on the grounds that the assessment as proposed would constitute "a regulatory barrier to the market", is illustrative of both the interplay between supervisory and regulatory parameters as well as of the difficulties surrounding common ESA initiatives.
} 
box-ticking exercises than incentives for supervisory convergence. It is no accident that enhancement of such tools has been a constant, albeit elusive, preoccupation in both review exercises (204 and 2019).

The ESAs are also full-time mediators both internally and vis-à-vis the other financial authorities - there would be no "network" otherwise. They act initially as mediators/arbiters and potentially, but only as a last resort, also as settlers of disagreements between supervisors; they participate in colleges of supervisors, concerning cross-border activities, where they have a role to promote and monitor the efficient, effective and consistent functioning of the colleges, notably by collecting and sharing all relevant information, overseeing the tasks carried forward by the competent authorities, requesting further deliberations and playing a legally binding mediation role to resolve eventual disputes between participating competent authorities; a specific "safeguard" theoretically in place so as to ensure that no emergency measures or binding mediation decision impinges on the fiscal responsibilities of member-states is more a limit on the ESAs' independence and will be analysed in the relevant section. Formal cooperation channels between the ESAs are provided for, most importantly a special "body", the Joint Committee, composed of the Chairs of the three authorities; in practice, however, it has struggled to find significance and a seamless mode of operation and has not proven to be an adequate forum for supervisory convergence. A Board of Appeal, composed by six members, two by each authority, has also been drawn up to decide on appeals against the decisions of one of the ESAs, but has remained largely unused, since no authority has shown a propensity to lodge an appeal against a decision of any of its twins.

In addition, the explicit attribution to the ESAs of the role of "Commission advisors" makes them privileged interlocutors of the European decision-makers on all issues connected with the financial sector. The advisory role gives them, at least in theory, powers of mediation and proposal directly stemming from the founding Regulations. I say in theory, because a recurrent, and justified, complaint from the ESAs concerns the non-establishment of both formal and informal channels of communication with the European institutions outside the remit of technical standards, the most blatant example being that the ESAs are hardly even consulted during the legislative process on matters of their competence. ${ }^{18}$

The mediation role of the ESAs should not be underestimated, nor should it be merged with the regulatory or supervisory activities. It is a specific and crucial task establishing both prestige and coordination, although it is rarely performed, or, in the case of colleges, it is being performed far from the limelight.

\subsection{Evolution towards separation}

The triplets have started growing up together but soon started going their separate ways. Four major facts have contributed to that.

The first has to do with the differences of the financial sector to which each of the ESAs is connected to. Banking was perceived, as we have seen, as the main market,

\footnotetext{
${ }^{18}$ The then Chair of EBA, Andrea Enria, specifically alluded to that (see The House of Lords Report on the "Post-crisis financial framework", 2016, Chap. 3, p. 3), but I have heard the Chair of ESMA, Steven Maijoor, also make the same comment.
} 
but the origins of the crisis and the looming shadow of the ECB soon showed that the relevant institution's real competences were rather narrow. The insurance sector, on the other hand, continuously gained importance as a market player, but was not as systemically important and as extended in scope as banking and capital markets. Thus, ESMA had, almost from the beginning, a special momentum: it dealt with the more extended and, up to then, the most under-regulated, and thus the riskier, sector; its Board was comprised of the Chairpersons of independent regulators, or regulators within regulators (in Germany, Ireland and some other jurisdictions), with a broad range of activities, whereas the representation at EBA is usually at directors level and in most member-states there are no independent insurance supervisors.

This initial trend was further enhanced by two political decisions, and consequent developments, of prime importance: the advent of the Banking Union and the launch of the Capital Markets Union by the European Commission.

The 2012 initiative, in the so-called "Five Presidents Report", to form a "Genuine Economic and Monetary Union" implying, inter alia, that the existing EMU was not genuine enough, resulted in the 2014 creation of the Single Supervisory Mechanism (SSM), a pan-European supervisor for the so-called "significant banks", lodged within the ECB but acting as a separate body; the Single Resolution Mechanism (SRM) followed in 2016. Those two new bodies, together with the not yet established but equally important and necessary third pillar, the European Deposit Guarantee Scheme (EDIS), constitute the Banking Union, a coordinated pan-European effort, with "ins" and "outs", but also with bridges connecting them, conceived in order to create a sounder and more efficient banking sector, mainly by severing the link between the banks and each sovereign state. It is undeniable that such a seismic change in the banking supervisory landscape would produce, and did produce, an important impact on the banking authority, the EBA. The impact had to do less with a loss of formal powers - the Commission was quick to declare that EBA's role was to be preserved and the ECB/SSM was to acquire supervisory tasks carried out by the national supervisors, not EBA - than with a sense of further shifting the centre of banking decisions and evolutions. What could not have been imagined at that time was that EBA, and the European financial world in general, would take another big hit following the British decision to exit the European Union, a decision resulting also in EBA needing to relocate to Paris.

Apart from the need to rearrange the relationship with the ECB and to requalify its role vis-à-vis the banks and the public, the advent of the Banking Union produced an immediate substantial change concerning the voting method of the EBA Board of Supervisors in order to accommodate the "ins" and "outs" division generated by members-states' participation or non-participation in the Banking Union. ${ }^{19}$ With a new status, a new seat and, in the midst of the second mandate, a new Chair, the EBA is certainly in a transitional phase.

ESMA, on the other hand, is on a continuously ascending slope. European financial markets needed strengthening and enhanced supervision and the regulatory landscape changed almost completely with the elaboration and entry into force of EMIR,

\footnotetext{
${ }^{19}$ For the adoption of technical standards, guidelines and recommendations, appeals and internal budgetary matters, a qualified majority voting was instituted, by an amendment to the 2010 founding Regulation, consisting of a simple majority of SSM participants and a simple majority of non-SSM member-states.
} 
MIFID2/MIFIR, MAR/MAD, new rules for funds and many other texts for which ESMA had to prepare technical standards'; international cooperation, especially in the field of derivatives, became all-important and the Commission was always asking for more. The launching, in 2014, of the Capital Markets Union (CMU), an ambitious long-term technical-political effort to strengthen the development and coordination of the European capital markets and facilitate cross-border flows, further enhanced ESMA's responsibilities and status. Although not formally in charge of the CMU, ESMA became de facto part of it, on top of its formal tasks. Satisfying recruitment needs, and a move to bigger premises in Paris, came first, added tasks by virtue of the 2019 review followed.

Brexit, the fourth major element, whatever its outcome and severity, will also play an important role in reshaping the landscape. What sector will it hit most? Will it destroy or merely change the dynamic of the CMU? If the UK were to move towards a Singapore-type economy, which authority would have to take the lead? Who will prepare and who will bear the cost, and the shock, of the transition? Will Brexit's advent lead to fresh political initiatives, perhaps primarily a quickening of pace for EDIS in order to complete the Banking Union? Logic dictates that all those systemic turbulences will result in a stronger role for the ECB and ESMA and possibly change in the overall supervisory regime.

The system is heading towards a new symmetry, which might well be asymmetric: EBA and ESMA are in Paris, EIOPA and the ECB in Frankfurt; ESMA is getting bigger, EBA is searching for a new role, EIOPA presides over Solvency 2 and not much else; Brexit is looming over everything. Many questions spontaneously arise: What is the value-added of EBA with the ECB/SSM as a pan-European supervisor? Would it make sense for ECB and EIOPA to merge? How could the deciders accommodate the growing-apart of ESMA? Is a single super-supervisor a possible answer to the Brexit challenges? Thus, the broader question of a possible functional rearrangement is clearly posed -and will be touched upon at the end of the present analysis.

\section{Where real power lies}

\subsection{The nomenclature puzzle}

The ESAs are by their very name "authorities", but this is a term without legal bearing in the EU: no other European authorities are called "authorities" and there is no definition or categorisation of such a term. In the founding Regulations (art. 5) all three ESAs are qualified as "Union bodies with legal personalities", but, again, this is a neutral, prescriptive and not inscriptive, term. In fact, if one wanted to fit the ESAs in one of the existing formal categories of EU bodies, one would have to accommodate with "agencies". They do in fact participate, and expand, the "agencification" tendency, which has gone hand-in-hand with the deepening of the European integration and the accumulation of its tasks, a tendency which could be seen as having progressed in three "waves": the genetic one, in the mid-1970s, which generated two agencies, the CEDEFOP and the EUROFOUND; the second-generation, in the 90s, 
accountable for eleven agencies, mainly connected with the internal market; and the big-bang since 2001, which resulted in the creation of 22 more agencies. ${ }^{20}$

Though they are not called "agencies", ${ }^{21}$ the three ESAs are agencies, ${ }^{22}$ albeit of a slightly different, and ultimately higher, order. They do stem from the need of the Commission to manage administrative burden by empowering technocratic bodies on whose expertise they can rely; they have as a central task to assist with "technical" work and to liaise with organised groups and the public at large; they have a high, albeit limited, degree of independence (more on that later); they are endowed with a proper legal personality; they have full-time Chairpersons, their decisions are taken by bodies representative of the member-states, their personnel is employed by, works for and is remunerated by according to the EU rules; ${ }^{23}$ they have financial discretion but are financially accountable to the European Parliament, the Court of Auditors, the European Anti-Fraud Office.

The ESAs, however, are not, "normal" agencies, they do not fit into any of the first three "waves", nor can they be said to constitute by themselves a "fourth wave" simply prolonging the existing tendency. In many important areas, they have significantly, and quantitatively, enhanced characteristics: they were born to face a real crisis and thus have a proclaimed systemic importance very few of the other agencies possess and, seen as a whole, they cover a field - the financial sector-wider than that of all the other agencies put together; their "expertise" is proclaimed clearly and unambiguously; ${ }^{24}$ they have been created, like no other agency, on the basis of a Treaty Article recognising the existence of EU "agencies" 25 and also by virtue of EU specific Regulations; their Boards are composed not by mere representatives of the member-states, but by persons representing, and at most cases heading, national supervisory institutions; their heads are not only accountable to the European Parliament, they are linked to it, and to the Commission, by their very mode of designation: the Commission comes up with a short list, the Parliament endorses the choice of the

\footnotetext{
${ }^{20}$ Sami Andoura and Peter Timmerman, "Governance of the EU: The Reform Debate on European Agencies Reignited", European Policy Institutes Network, Working Paper no 19, October 2019. For agencies in general see also Majone [10]; Chiti [3]; Vos [19]; Thatcher [15]; Vos/Everson [18].

${ }^{21}$ Nowhere in the founding Regulations is the term "agency" to be found. The only official linking, and only for EIOPA, with the other "agencies" exists in Annex II of Commission Communication 2009.52, whereby it is stated that "the cost of setting up EIOPA has been estimated according to three cost categories ... in line with the classification used in accounts of the existing EU regulatory agencies". This constitutes, in my view, too weak to link to proclaim, as do Van Meerten/Ottow [17], that "it is therefore safe to say that the ESAs will have the status of an agency"-if but that they mean of a "simple" agency.

${ }^{22}$ In the 2014 ESAS' Review: "Report from the Commission to the European Parliament and the Council on the operation of the ESAs and the EFSF" (COM 2014/509) it is said that "the ESAs are decentralised agencies" which have an "important role in contributing to the implementation of Union policies", but they remain "distinct from European institutions and their role in the regulatory process has to be assessed within the limits posed by the Treaty".

${ }^{23}$ Recital 61 of the founding Regulations.

${ }^{24}$ Recital 23 of all three founding Regulations: “... the Authority (all of them) is the (meaning: the only) actor in close contact with and knowing best the daily functioning of the financial markets" and Recital 24: “... given the technical expertise of the Authorities".

${ }^{25}$ Article 236 TFEU referring to the legality of "acts of bodies, offices and agencies of the Union". Concerning, however, delegation of powers to agencies under Articles 290 and 291 TFEU, Hofmann [7], finds the system inadequate.
} 
Board of Supervisors; their budget is covered by both the EU (60\%) and the memberstates $(40 \%)$ and is scrutinised on a much more substantive basis; the "network element" is visceral, not only desired as in the other agencies: the ESAs simply cannot function-in fact: do not exist-if they do not constantly interact within themselves, with the national competent authorities, with the Commission.

So, even leaving apart the issue of competences, which we have already touched upon in the second section and will soon revisit from a legal angle, it appears that the ESAs were conceived and created as "Agencies Plus". Their name, after all, is not fortuitous or without significance: we cannot ignore the fact that the previous financial "Committees" were replaced by "Authorities" and not by "Agencies". Because the name is completed by substantive characteristics, the ESAs are something more, both from a legal and competences viewpoint, than the Committees they were created to substitute: they are something qualitatively higher, symbolic-wise and competencewise, from the agencies of the three first "waves", although they remain, on a formal level, something less than European "institutions" created by primary legislation. The transition from "agency" to "authority" is subtle but real: it has also, albeit indirectly, been admitted by EU case-law.

\subsection{The legitimation quest}

Without clarifying the nomenclature issue, ${ }^{26}$ the all-important "short-selling decision" 27 of the European Court of Justice, goes clearly in the direction of establishing the qualitative difference between "agencies" and "authorities": not only did it find that the power of ESMA to adopt emergency measures on the financial markets of member states on the basis of the Short-Selling Regulation ${ }^{28}$ is compatible with EU law, but it also clarified, concerning the powers that may be lawfully exercised by the ESAs, that said entities, although not possessing any autonomous power going beyond those which were attributed by their founding Regulations, they nevertheless possess, because of their very nature and both legal and substantial characteristics, powers $^{29}$ going beyond delegation, which was, according to the "Meroni doctrine", 30 the basis for the delineation of the competences of "agencies" up to that moment.

\footnotetext{
${ }^{26}$ The decision alternately and without specification uses the terms "bodies", "authorities" and "entities".

${ }^{27}$ Judgement C-270/2012, United Kingdom v. Parliament and Council of the EU.

${ }^{28}$ Regulation EU 236/2012 of the European Parliament and Council.

${ }^{29}$ The Court made a subtle distinction between "measures of general application having the force of law", which would not be permitted, and "measures of general application", which it accepted as lawful if well circumscribed.

${ }^{30}$ Case 9/1956, Meroni \& Co, Industrie Metallurgiche S.p. A v. High Authority [1957-1958], ECR 133. In "Meroni" the Court judged that, under the Treaty of Rome, only executive powers may be delegated and not discretionary ones and, even then, delegation to autonomous bodies is considered to be acceptable as long as Commission retains control powers to monitor how these delegated tasks are being carried out. The difference of both legal and substantive background (in "Meroni" the entity to which delegation was given was not an agency, but a private body, the so-called "Brussels agencies", and the delegation was not provided by a community act but by the High Authority), and also the fact that the short-selling Regulation gave ESMA decision-making powers (to adopt emergency measures and eventually to temporarily prohibit short-selling) while "Meroni" stopped short of decision-making, should from the outset make one very cautious in transposing in toto the "Meroni" judgement to the context of ESMA and, more, generally, the ESAs. In that line, H. Van Meerten and A. Ottow, op.cit. Merijn Chamon, "EU Agencies between Meroni
} 
Thus, the acquis of the "short-selling" decision was not, in my opinion, so much the link with the "Meroni doctrine", but the fact that mere delegation was surpassed, ${ }^{31}$ and a specific type of autonomy was enshrined.

The importance of the ruling, ${ }^{32}$ other than being the first and up to now unique case dealing with the ESAs' powers, is that it vests supervisory authorities with enhanced powers vis-à-vis mere agencies based on a) their role in securing financial stability in the European Union: "ESMA is endowed with powers of intervention to cope with adverse developments which threaten financial stability within the Union and market confidence", b) their competences stemming from a community act and being "precisely delineated and amenable to judicial review", ${ }^{33}$ c) their exclusive expertise in the financial sector: "ESMA is vested with certain decision-making powers in an area which requires the deployment of specific technical and professional expertise". In the "short-selling decision" the ECJ has ruled, in a nutshell, that ESMA and by extension all three ESAs are European entities with powers which, when found to be correctly circumscribed, are recognised as both extensive and protective. The ruling also tells us, even more importantly from a legal viewpoint, that the ESAs may be attributed by secondary EU legislation competences not explicitly referred to in the founding Regulations as there was no mention of short-selling prohibitions in those texts, nor of a direct supervision of the Credit Rating Agencies, which was transferred to ESMA by deed of an amendment to the CRA Regulation, provided that they fall within their general tasks and systemic role.

What the ruling takes great care in not doing is admitting that the ESAs are vested with a "very large measure of discretion"-in fact it certifies the opposite ${ }^{34}$ - , because that would be contrary both to the "Meroni-Romano principles" and, more importantly, to the Treaty itself. However, the "circumscribed systemic extension", by way of secondary legislation, which the ruling admits, might be a different legal notion, but ends up giving the ESAs, especially when measured in practical terms, not very different powers from those of EU "institutions".

On top of extended competences enshrined in legal texts and recognised as such by the Courts, and expertise attributed and acted upon, the third element procuring legitimation to the ESAs is the perception by the financial milieu and by the public at large. The obligation to consult in a formal way before drafting technical standards

and Romano or the Devil and the deep Blue Sea", in Common Market Law Review, no 48, 2011, also notes that "the differences between the factual and legal contexts in which the Brussels Agencies in Meroni and the current day EU agencies operate are fundamental in nature".

${ }^{31}$ Though the ruling constantly referred to "delegation of powers", it concluded that, regarding ESMA, such "delegation" was valid even though it did not "correspond to any of the situations defined in the relevant Articles of the Treaty on the Functioning of the European Union", thus in fact surpassing the notion of delegation as enshrined in "Meroni". In that sense, it is true that "the decision appears to deprive the Meroni principle ... of all real effect as Article 28 of the short selling regulation appears to give ESMA significant discretion without oversight by an EU institution": "The European Court's dismissal of the UK's challenge to the short selling regulation", Mayer-Brown, Legal Update, February 2014.

${ }^{32}$ Costa [4].

${ }^{33}$ The "Romano case-law", i.e. Case 98/80, Giuseppe Romano v. Institut National d' Assurance maladieinvalidite [1981], ECR 1259, fundamental concerning the conferral of power, was used as a basis.

${ }^{34}$ Argument no 54 of the ruling. 
and for every other type of "quasi-rulemaking" activity; 35 the also formalised setting up of Stakeholders Groups for all three ESAs; ${ }^{36}$ and the various transparency requirements such as: appearance of the Chairs before the European Parliament, public consultations and communications by own initiative, publication of all decisions, ${ }^{37}$ rules of procedure, ${ }^{38}$ financial accounts ${ }^{39}$ formal proposals, facts, analyses and workin-progress in the respective websites, obligation to consult NCAs, duty to justify decisions and give reasons for actions, ${ }^{40}$ most notably by publishing reasoned feedback to responses received: all those practical elements contribute to the perception of the ESAS as legitimate authorities ${ }^{41}$ acting on behalf of the public interest. A measure of their success is that the financial industry, in the various forms and groups which give voice to also legitimate but non-public and non-general interests, both collaborates and criticizes the ESAs. The latter without the former would create legitimacy and functional problems, the former without the latter would be a sign of the ESAs not doing their jobs correctly. Of course, legitimation is a different concept from legitimacy, whereby the central question is the democratic one: how can such authorities have extended powers without being elected bodies and to whom are they accountable if they are to remain "independent"?

\subsection{The independence test}

Agnostic towards the nomenclature issue and encompassing the legitimation issue, the notion of "independence" provides the litmus test. Independence is, by definition, what the "independent authorities" strive for and need in order to perform their tasks. Specifically for the ESAs, such independence is formally and unambiguously established in the founding Regulations: Article 1 para 5 last indent states that "when carrying out its tasks, the Authorities shall act independently and objectively and in the interest of the Union alone"; Article 42 specifies the independence of the Chairpersons and the members of the Board of Supervisors using (almost) the same language $^{42}$ and adding that they "shall neither seek nor take instructions" and that Union institutions and bodies, as well as public or private bodies "shall not seek to influence

\footnotetext{
${ }^{35}$ All three ESAs have adopted very similar "public statements on consultation practices" (ESMA in 2011, EBA and EIOPA in 2012), thus making much clearer and more formal the founding Regulations' provision (Art. 16 para 2) that consultations hall be conducted "when appropriate".

${ }^{36}$ Art. 37 of the founding Regulations.

${ }^{37}$ Article 39 para 5 of the founding Regulations, with the caveat that such publication may not take place when it is "in conflict with the legitimate interests of financial institutions in the protection of their business secrets or could seriously jeopardize the order function, integrity and stability of the financial markets".

${ }^{38}$ Article 44 para 3 of the founding Regulations.

${ }^{39}$ Article 64 para 6 of the founding Regulations.

${ }^{40}$ Article 39 para 2 of the founding Regulations.

${ }^{41} \mathrm{~J}$. Mendes, "La legittimazione delle isituzioni dell'UE tra istanze istituzionali e democratiche", in Marchetti/de Lucia (eds.) [11], argues that expertise is the main ground for legitimation for EU agencies. Maurizia de Bellis, op.cit, speaks of a "procedural paradigm of legitimation" put into light by the "short-selling" decision and consisting of "procedure and expertise". A third element, public perception, is added here.

42 "The interest of the Union alone" becomes "the sole interest of the Union as a whole" ... but I am not proposing to seek any hidden meaning in such linguistic subtleties.
} 
them"; identical independence guarantees are to be found for the members of the Management Board (Article 46), while for the Chairperson (Article 49), the Executive Director (Article 52) and the members of the Board of Appeal the phrasing refers only to the instructions and the influence. Moreover, Recital 45 of the founding Regulations enshrines the ESAs as "independent advisory bodies to the European Parliament, Council and the Commission", while Recital 59 explicitly links an "autonomous budget" (which is in fact not so autonomous, as we shall see) to the guarantee of a "full autonomy and independence" of the ESAs.

In theory things seem clear: the ESAs perform their tasks, as circumscribed in the founding Regulations and eventually interpreted by the Courts, in collaboration with many other institutions, ${ }^{43}$ at EU or the national level and at the international stage, ${ }^{44}$ as they wish and without taking instructions and being influenced by their public and private, formal and informal, interlocutors. In practice what one should look at is the extend and impact of their decisions, the relationship with the main EU organ they collaborate with, namely the Commission, the power play with the member-states and the market forces and the resources available for the fulfilment of their tasks.

We have already seen that the spectrum of the ESAs' competences is wide and that their main task, setting regulatory technical standards, is in a large degree discretionary, since the Commission may not endorse or amend the draft standards only in "very restricted and extraordinary circumstances". The range of instruments and procedures at their disposal is extensive and self-driven. They have the right to request and to be provided with all necessary information, ${ }^{45}$ they may conduct inquiries not only by request but also by their own initiative ${ }^{46}$ and give opinions, on matters of their speciality, by their own initiative. ${ }^{47}$ On the other hand, the ESAs are dependent upon the Commission in order to start drafting technical standards, they lack enforcement powers of even their own decisions, and they have scant influence on the so-called Level 1 legislative process. While it is not accurate to say that they have insufficient independence from the Commission, ${ }^{48}$ it would not be far from the truth to admit that "big" national supervisory authorities like the FCA are more autonomous and influential at the practical level ${ }^{49}$ — but still ESAs are more prestigious.

The main obstacle to independent decision-making seems to be posed by the "safeguard mechanism", whereby member states may first notify to one of the ESAs and the Commission and then appeal before the Council, in cases where they feel that an ESA decision has impinged on their fiscal responsibilities. ${ }^{50}$ This mechanism, however, is, firstly, applicable only for decisions in emergency situations, which, as we

\footnotetext{
${ }^{43}$ From that angle, it is correct to speak of an "interdependence of the independence" as does Lafarge [9].

${ }^{44}$ Mainly through negotiating, signing and implementing Memorandums of Understanding (MOUs) with non-EU authorities and participating in equivalence decisions (the final decision belongs to the Commission).

${ }^{45}$ Recital 46 of the founding Regulations.

${ }^{46}$ Article 24 para 4 of the founding Regulations.

${ }^{47}$ Article 34 para 1 of the founding Regulations.

${ }^{48}$ As stated in the UK House of Lords, op.cit.

${ }^{49}$ Ibid.

${ }^{50}$ Article 38 of the founding Regulations.
} 
have seen, are far from constituting the bulk of the ESAs decisions; secondly, remains at international and not national level, since the ultimate decision is to be taken by the Council; and, thirdly, has never been put into practice up to now: it is there because some member-states asked for it as a reassurance during the parliamentary scrutiny. If, in theory, it seems contrary to the movement of "Europeanisation" of the financial supervision, ${ }^{51}$ reality on the field has given impetus to such movement, initially through the competences attributed to the ESAs and, as the authorities evolved, through the attribution of more direct supervisory powers (see last section).

Regarding the relationship with member-states, the most problematic aspect is the independence of the ESAs vis-à-vis the national competent authorities, which deserves to be qualified as weak. ${ }^{52}$ The role of national representatives sitting on the ESAs Boards is hardly rendered less "national" by the founding Regulations' stipulation that such members shall act "in the interest of the Union alone" 53 - a push in favour of "more European spirit" seems both tautological and necessary but is far from easy, though. NCAs' decisions are not sanctioned by the ESAs, most of the time they are not even known to them, and "convergence" is a nice word to which a) the supervisors still search the meaning, b) should they find it, it would be mainly put into practice by the NCAs. Operational independence, on the other hand, is high, given that there is little interference with the ESAs' work, the industry's interests are represented much more by the various associations than by the traditional lobbyists and the overall balance between public-private interests rarely ends at the detriment of the former. A subtler way to give echo to the industry's preoccupations, other than the formal consultation procedures, is through the work of the ESAs' Committees, which are headed by members of the Board of Supervisors and, in most of the highprofile cases, members coming from the "big" countries or from ones with large financial industries: a good example is provided by the most complex and sensitive technical standards of MIFID2/MIFIR being prepared by ESMA under the tutelage of the UK representatives (in a pre-Brexit era...). But again, the name of the game being collegiality and the first reflex being protection of the ESAs' reputation and not the industry' s interests, the balance has been, based on my experience, satisfactorily preserved.

Resources pose a more substantive problem. Given the tasks of the ESAs, and especially ESMA's, a staff of less than 200 people, however qualified and hard-working they turn out to be, is almost derisory. ${ }^{54}$ It has been a factor in focusing so much on the regulatory aspects and somewhat neglecting, or underestimating, consumer protection and supervisory convergence. The budget is also unsatisfactory, both because it is made up exclusively of "public contributions" (by the EU budget and all the NCAs according not to their market share but to the member-state's relative share in the overall EU budget) and because the degree of flexibility of the ESAs to impose

\footnotetext{
${ }^{51}$ Francois Lafarge, op.cit.

${ }^{52} \mathrm{M}$. de Bellis, op.cit.

${ }^{53}$ Both the European Parliament Resolution of 22 March 2014 and the Commission's 2014 Report on the ESAs found that "national views rather than EU interests dominate the Board proceedings".

${ }^{54}$ It is the equivalent of a mid-range supervisory Authority, like the Greek one, and five to twenty times smaller than the German, French or UK Authorities (4000 employees).
} 
real choices is restricted. Especially at ESMA, one of the more frustrating experiences I have experienced is asking, each year, the Commission for staff and liberty to prioritise and getting half-hearted and bureaucratic responses. This makes altogether more disappointing the fact that the budget mechanism and logic has not substantially changed despite such recommendations in both ESAs reviews and especially the second-as we will see in the final section.

On balance, I would tend not to downplay the real independence of the ESAs. Their acts are best qualified as regulatory sui generis acts, ${ }^{55}$ meaning that they have a higher degree of autonomy than most of the other EU agencies and approach that of EU institutions. They are publicly prominent and respected. They depend much on the national supervisors, less on the Commission and are not constantly in the radars of the Council, which has, as the French would so eloquently say, other cats to put under the whip. Most of the time, the balance of power goes their way when they confront the financial industry. If they lack, and they do lack, resources, they make it up by enhancing their reputation and momentum. Which does not mean that they should stay forever as they have been constructed: a bit experimentally and in too fragmented a way, as we have seen and will now revisit in order to close the cycle.

\section{Review or reform}

\subsection{Tale of two reviews}

In a way not dissimilar to other EU texts of the same calibre, the founding Regulations of the ESAs provide for a review procedure on a three-year basis. Unlike other texts, however, and thus showing that the ESAs are both experimental and hybrid EU bodies, this particular review is circumscribed in detail, both concerning the fields it shall cover and what it shall have to look at more fundamentally. Convergence seems to be the primary field (points a and c of Article 81 para 1), followed by crisisprevention and systemic risk (points c and d) and then some disparate and, frankly, secondary, issues, such as colleges, the safeguard clause and the mediation role. More interestingly, para 2 of Article 81 preordains that the review should "examine", which means that it might possibly re-appraise, the sectoral separation of the three ESAs, the possibility of a "twin-peak" approach, i.e. a distinction between prudential and conduct-of-business tasks and their repartition to separate regulators, the possibility of a "single seat" 56 the overall architecture of the EFSF, as well as the adequacy of the ESAS' resources. Thus, the review is meant to be both technical and substantial, the "philosophical" questions surrounding the creation of the ESAs remaining alive.

The first review, ${ }^{57}$ which took place in 2014 , as provided for in the founding Regulations, was, logically, of a general nature. The Commission, after conducting a broad consultation, and reviewing the ESAs as a whole without looking separately at

\footnotetext{
${ }^{55} \mathrm{H}$. van Meerten and A, Ottow, op.cit.

${ }^{56}$ Expressed in the 2014 Commission Report on the ESAs.

${ }^{57}$ Report from the Commission to the European Parliament and the Council on the operation of the ESAs and the EFSF, COM 2014/509.
} 
each Authority, found that "overall the ESAs performed well"; this judgement, however, was limited to their having "built functioning organisations", having "started to deliver on their mandates" and having "developed their own profiles". Hence the proposals were also of a general nature and for future use-no changes took place following this first review: increasing the focus on supervisory convergence and consumer protection and enhancing internal governance with particular mentions to Stakeholder Groups- to be "composed in a balanced way"-, work of ESA staff within preparatory bodies - "to be reinforced"-, the role of the Joint Committee"to be enhanced"-, the authority of the Chairpersons - "to be enhanced". The Report set as short-term priorities the re-examination and fine-tuning of deadlines and timelines for technical standards.

Some medium-term ideas so called "potential main areas for possible improvement" have been sketched in the first Report, which were to find an echo in the second, and more substantive, review exercise: they relate to governance, not only strengthening the position of the Chairperson but also "amending the composition and mandate of the Management Board"; funding arrangements improvements going towards "ideally abolishing EU and national contributions"; direct access to data and extension of the ESAs initial mandates with further tasks; IFRS enforcement, shadow banking and direct supervision were given as specific but not exhaustive examples.

The ground for the next review was set, both the founding Regulations and the first review pleading for changes. The initial reflex of the Commission, in 2017 on the date on which, normally, the review had to be finalised, was bold enough: lodged within the broader Capital Markets Union scheme and under the title "reforming the European Supervisory Authorities", the legislative package proposed, inter alia, a new governance structure with a full time Executive Board; a new funding structure, independent from national supervisors and consisting of contributions by industry and market participants; new objectives, covering technological innovation and new risks; and more direct supervision powers, most notably for ESMA, covering benchmarks, data service providers, prospectuses and funds. The distinction between the banking sector which "already benefits from consistent supervision by the Single Supervisory Mechanism within the Banking Union" and EU capital markets "supervised at national level" and "in need of further integration" whilst EU insurance and pensions markets are deemed to simply require "further convergence of supervisory practices" 58 is made clear, as is the urge for the EU "to use the current window of opportunity in order to adjust it structures". Major events, such as the progress of the Banking Union and the launching of the Capital Markets Union, Brexit, the exit from the financial crisis and the slow return of growth in the EU, as well as accumulated experience regarding the functioning of the ESAs and the EU financial sector, were the drivers of this new-found boldness.

Political reality proved different. Member-states in the Council and members of the ECON Committee in the European Parliament were far less happy with this obvious step towards "Europeanisation" of financial supervision. The process stalled, and then dragged on. The review was merged with the discussion of the legislative

\footnotetext{
${ }^{58}$ Commission Communication reinforcing integrated supervision to strengthen Capital Markets Union and financial integration in a changing environment, COM 2017/542.
} 
package of the Commission and with the progress report on the CMU. New priorities emerged, most notably in 2018, with the need to combat money-laundering after serious cases erupted in unexpected places and with grave consequences. ${ }^{59}$ Finally, at the last gasp before the European elections, a political agreement was reached between the European Parliament and the Council on the 21st of March 2019, and endorsed as legislation by the European Parliament on the 18th of April: its key features were by no means unimportant, but, reform-wise, substantially edulcorated the initial Commission proposal.

Anti-money-laundering became the first priority and EBA was entrusted with the relevant mandate; convergence of supervisory practices was to be carried out by strengthening peer reviews (to be headed by ESA staff), by institutionalising coordination groups of the ESAs and competent authorities on concrete cases after a request by at least five members of the Board of Supervisors of one of the ESAs and by entrusting EIOPA with specific supervisory tools (possibility to assist national supervisors, introduction of collaboration platforms); ESMA' s direct supervision was extended to coordination in market abuse cases (by issuing opinions on the follow-up of cases with cross-border implications brought before the Authority), critical benchmarks (by authorising and supervising their administrators at EU level and recognising non-EU administrators of benchmarks used in the UE) and data-reporting serviceproviders (authorisation and supervision) — it was denied for prospectuses and funds, which proved to be the main bones of contention during the examination of the proposals by the Council and the Parliament, and also for delegation or outsourcing of substantial activities to third countries; the supervisory fine-tuning included extending consumer protection (especially product intervention) powers, promoting FinTech and sustainable finance (by monitoring the introduction of environmental, social and governance criteria and taking them into account in all their activities) and introducing an "alert and convergence system", whereby the ESAs can alert the Commission on significant issues relating to legal acts and raised by market participants; the governance reform concerning the creation of a permanent Management Board was scrapped and instead only the Chair's position was strengthened: he/she shall hitherto be appointed by the Council after confirmation by the European Parliament and shall possess more powers in dispute settlements and breach of union law proceedings; the funding reform was also scrapped, ${ }^{60}$ despite having been highlighted in both reviews, but was somehow sweetened by the promise of a significant increase in human resources, especially for ESMA. All in all, the 2019 review ${ }^{61}$ did not produce a real reform for the ESAs. The debate must be kept open by other means.

\footnotetext{
${ }^{59}$ Commission Communication for strengthening the Union framework for prudential and anti-money laundering supervision for financial institutions. It followed and expanded similar preoccupations voiced in Commission President's Juncker "State of the Union" address of the same year.

${ }^{60}$ The possibility for ESAs to charge for publication, training and other charges specifically requested by supervisors is rather anecdotic.

${ }^{61}$ Less prominent changes are: carrying out cost-benefit analyses when developing guidelines and recommendations; slightly amending the breach of law procedure by enabling the ESAs to directly address requests for information to other competent authorities or market. participants; triggering settlements of disagreements also by ESAs' own initiative; developing "Strategic Supervisory Plans".
} 


\subsection{The reform conundrum}

As in most fields of European Union policy, times are changing but institutions plough on. Financial markets are no exception, albeit they possess the peculiarity of being directly dependent upon evolutions in the real world. The three ESAs have completed an eight-year cycle by proving themselves and proving also the inbuilt deficiencies of the system they participate in: fragmentation, "one-size-fits-all" architectural design, absence of enforcement capacity, conflict between national and supra-national reflexes. Moreover, an ECB-driven Banking Union, an ambitious Capital Markets Union and, impinging on both as well on any financial activity, Brexit, are too momentous developments to be ignored. ${ }^{62}$

If one wants the ESAs to become "true" regulatory agencies, ${ }^{63}$ one has, after two tests, to abandon the idea that this can brought about through the cyclical review procedure. Such a review, useful as it is, cannot change the inner structure of the system and the fact that the three ESAs are seen in conjunction and as if they were equal parts of a whole, while reality has shown that both the needs and the systemic and practical importance of each of the authorities are different. A reform would have, firstly, to rethink who does what and for what purpose, and, secondly, to be either "constitutional", i.e. touch upon the Treaties, or change fundamentally the Level 1 texts.

It is always tempting, and it sounds clever, to plead for deep changes; it is less bold and less intelligent, however, to ignore the political implications, which, in the EU, lead, most of the time, to an impasse. Both constitutional and legislative reform would face high obstacles and steep political opposition. A change of Treaties going in the direction of "institutionalising" the ESAs would presuppose that there would be political momentum to "reopen" primary law arrangements on a larger scale and that the complicated arithmetic of such an enterprise could come to fruition. There is a high improbability for either condition to be met. Moreover, I am not personally convinced that a Treaty change is needed in order to modify the structure and strengthen the position of the ESAs: the "short selling decision" has opened the way and the 2019 proposed changes, even if they ended up not being as bold as the initial proposals, have shown that reform can be brought about through secondary legislation. Of course, the need, and the difficulty, to find broad political support remains.

Having seen what the ESAs do and what they lack, and also having taken into account, the evolution in the financial markets through the so-called "years of the crisis"- because the crisis the ESAs were supposed to combat far from disappeared with the birth of the ESAs - one could at least outline the contours of a more effective supervisory mechanism. ESMA has appeared by far as the most important of the three authorities and it is not any more justified that its reinforcement goes hand-in-hand with similar moves for its two twins. More direct powers of supervision for ESMA are essential: capital markets regulation has become, whether we like or not, essentially cross-border and giving the final word on all issues to national competent authorities

\footnotetext{
${ }^{62}$ Davies [5].

${ }^{63}$ Simoncini [14]. The concept of "true supervision by a real supra-national body" is also retained by $\mathrm{H}$. van Meerten and A. Ottow, op.cit.
} 
does not make sense both from a level-playing field and a supervisory convergence perspective. More direct powers mean also more "European decision-making" processes: although the proposal has not been able to overcome national resistances in the course of the 2019 review, it still makes eminent sense to attribute some specific powers to a denser permanent collegial organ with simple voting modalities. It is also only logical that ESMA should evolve into a hub to oversee-not manage or stifleFinTech, a focal point for Capital Markets Union and for Brexit consequences, as well as an autonomous negotiator of the "European interest", in place of the Commission, in the international financial regulation scene, especially regarding equivalence decisions. Its staff should exponentially increase, and financing modalities revised and "liberated" from complete dependency on public contributions.

The objective primacy of ESMA raises the question of the overall architecture of the system. The single-supervisor idea needs to be, if only intellectually, revisited. A single authority would be financial-markets-oriented, with special departments for other tasks, chief among which would be the battle against money-laundering. ${ }^{64} \mathrm{At}$ the very least such a scheme would solve one of the main deficiencies of the existing "network", which is the unsatisfactory level of cooperation between the three ESAs; it would also contribute to create a more balanced approach with the supervisory elephant-in-the-field, the ECB. If one were to look for inspiration in the "twin peaks" approach, one would probably plead for merging EBA and EIOPA, ESMA, in that case, acting as a market authority and the new authority as a prudential regulator. ${ }^{65} \mathrm{It}$ should not be forgotten that a) the "overall architecture" issue is officially left open by virtue of the review clause of the founding Regulations and b) the de Larosière Report had envisaged, and even recommended, moving to a system comprising only two authorities upon an early review of the EFSF. ${ }^{66}$ Whatever its problems, the Commission has shown that it is neither risk-averse nor shy in proposing reform initiatives. Recognition of the reality, boldness and the creation of political impetus are mostly required from the co-legislators - and the financial market participants could play in important role in creating this impetus. ${ }^{67}$

"Victims" of their overall success, the ESAs find themselves in a "Gattopardo"like situation: they have to change in order to remain valid. No other Jacques de Larosière exists, but a least the insiders know and should support his vision.

\footnotetext{
${ }^{64}$ Notwithstanding the proposal to attribute EBA a central role for money-laundering, the Commission opened an option, in July 2019, of creating a separate authority for that task.

${ }^{65}$ This idea has already been floated by the Commission in the course of the public consultation of the 209 review of the ESAs.

${ }^{66}$ De Larosière Report, op. cit., recommendation 24: "the first Authority would be responsible for banking and insurance prudential issues as well as for any other issue relevant for financial stability; the second Authority would be responsible for conduct of business and market issues". This recommendation is explicitly referred to in the Commission 2017 public Consultation paper in view of the 2029 ESAs review.

${ }^{67}$ Though apparently, if one were to judge by the Joint Trade Associations (Invest Europe, Insurance Europe, European Fund and Asset Management Association, Pensions Europe, European Banking Federation, FESE, AFME) views on the review of the EFSF (letter dated 25 February 2019), market participants seem to be very cautious of fundamental change and "urge that any proposed changes ... should primarily address proven gaps and shortcomings that prevent the NCAs and ESAs from fulfilling their current mandates".
} 
Publisher's Note Springer Nature remains neutral with regard to jurisdictional claims in published maps and institutional affiliations.

Open Access This article is licensed under a Creative Commons Attribution 4.0 International License, which permits use, sharing, adaptation, distribution and reproduction in any medium or format, as long as you give appropriate credit to the original author(s) and the source, provide a link to the Creative Commons licence, and indicate if changes were made. The images or other third party material in this article are included in the article's Creative Commons licence, unless indicated otherwise in a credit line to the material. If material is not included in the article's Creative Commons licence and your intended use is not permitted by statutory regulation or exceeds the permitted use, you will need to obtain permission directly from the copyright holder. To view a copy of this licence, visit http://creativecommons.org/licenses/by/4.0/.

\section{References}

1. Anderson, T.: Future system for EU supervision-will it work? Economic Review 2/2010

2. Busch, D.: A stronger role for the European Supervisory Authorities in the EU27. In: Danny Busch, Emilios Avgouleas, Guido Ferrarini "Capital Markets Union in Europe" (2018)

3. Chiti, E.: The emergence of community administration: the case of European agencies. Common Mark. Law Rev. 2(37), 309-343 (2000)

4. Costa, M.: The EU's Financial Supervisory Authorities: Mind the accountability Gap. In: eulawanalysis.blogspot.gr, 2014/01

5. Davies, H.: What lies ahead for the European Union's Regulatory Authorities? Eur. Financ. Rev. (2014)

6. De Bellis, M.: Procedural Rule-Making of European Supervisory agencies (ESAs). An effective tool for legitimacy? In: TARN Working Paper 12/2017

7. Hofmann: Seven challenges for EU administrative law. Review of European Administrative Law (2009)

8. Kost de Sevres, N., Sasso, L.: The new European financial Markets Legal Framework: a Real Improvement? Electronic form at ssrn.com

9. Lafarge, F.: L'independence des Autorites Europeennes de Surveillance. In: cairn.info (2016)

10. Majone, G.: The new European Agencies: regulation by information. J. Eur. Public Policy 4(2), 262275 (1997)

11. Marchetti, B., De Lucia, L. (eds.): L'amministrazione Europea e le sue Regole (2015)

12. Moschella, M., Tsingou, E. (eds.): Great Expectations, Slow Transformation: Incremental Change in Post-Crisis Regulation ECPR Press, Colchester (2013)

13. Scholten, M., Ottow, A.: Institutional design of enforcement in the EU: the case of financial markets. Utrecht Law Rev. 10(5), 80-91 (2014)

14. Simoncini, M.: Legal boundaries of European supervisory authorities in the financial markets: tensions in the development of true regulatory agencies. Yearb. Eur. Law 1(34), 319-350 (2015)

15. Thatcher, M.: The creation of European regulatory agencies and its limits: a comparative analysis of European delegation. J. Eur. Public Policy 18(6), 790-809 (2011)

16. Tsangas, G.: The Regulatory Powers of the European Supervisory Authorities: Constitutional, Political and Functional Considerations, University of Bristol Law School online publications (2016)

17. Van Meerten, H., Ottow, A.: The proposals for the European Supervisory Authorities: the right (legal) way forward? In: ssrn.com

18. Vos, E., Everson, M.: European Agencies: what about the Institutional Balance? In: Maastricht Faculty of Law, Working paper no. 4 (2014)

19. Vos, E.: Reforming the European commission: what role to play for European Agencies. Common Mark. Law Rev. 5(37), 1113-1134 (2000)

20. Wymeersch, E.: Europe's New Financial regulatory Bodies. Electronic version available at ssrn.com 